\title{
Urea Decreases Specific Ion Effects on the LCST of PMMA-block-PDMAEMA Aggregates
}

\author{
João Carlos Perbone de Souza \\ Instituto de Ciências Exatas, Universidade Federal de Alfenas - UNIFAL-MG \\ Fábio Herbst Florenzano \\ Departamento de Engenharia de Materiais, Escola de Engenharia de Lorena - EEL, \\ Universidade de São Paulo - USP
}

\begin{abstract}
Urea is a well-known additive used as a mild protein denaturant. The effect of urea on proteins, micellar systems and other colloids is still under debate. In particular, urea has shown interesting effects on the ion binding in systems like charged micelles, vesicles or Langmuir-Blodgett films. The urea effect on polymeric aggregates in water is still an open field. For instance, the additive may affect properties such as cmc, LCST, UCST and others. In particular, LCST is a property that can be very convenient for designing smart systems that respond to temperature. Previous studies have indicated that the LCST of positive charged copolymers aggregates based on poly[N-dimethyl(ethylamine methacrylate)], PDMAEMA, can be nicely modulated by anions in aqueous solution and such phenomenon depends on the nature of the anion present. In this work, it has been demonstrated that urea also affects the LCST of PMMAblock-PDMAEMA aggregates in aqueous solution. In addition, in the presence of high concentrations of the additive, the specific behavior of the anions is lost, supporting the general mechanism of urea reducing the differences on ion binding to surfaces in aqueous solutions. To the best of our knowledge, this is the first time those phenomena are shown in polymer micelles.
\end{abstract}

Keywords: Hofmeister Series, urea, LCST, ion binding, PMMA-b-PDMAEMA.

\section{Introduction}

Urea is a very interesting and valuable additive, widely used as a protein denaturant but having also effects on systems like micelles, vesicles and reverse micelles ${ }^{[1,2]}$. Despite these very known actions of this molecule, the exact mechanism of urea-driven denaturation is still under debate $^{[3,4]}$. Many factors may be involved in denaturation, including the influence of urea on the ion binding to charged groups and surfaces. In that sense, one of the most intriguing urea effects is its ability to reduce ion specific effects on colloidal systems ${ }^{[5]}$.

Recently, our group has showed that properties like the Lower Critical Solution Temperature (LCST) of poly(methyl methacrylate)-block-poly[(2-dimethylamino) ethyl methacrylate] (PMMA- $b$-PDMAEMA) aggregates in water are affected by ions in a specific way ${ }^{[6]}$. The phenomenon was understood as due to a higher binding constant of anions like perchlorate to the positive surface of the polymeric aggregates, hindering the electrostatic repulsion and allowing the transition at a lower temperature. Being urea an additive that affects ion binding, its effect on such systems must be also noticeable.

Besides all the interest on urea, there are few studies focusing on its influence on ion binding to polymer aggregates in water. If urea acts as a modulator of ion binding, it can also be useful as a controller of polymeric aggregates properties in solution, such as critical micelle concentration, viscosity and thermoresponsiveness.
Homopolymers and copolymers of poly[(2dimethylamine)ethylmethacrylate], PDMAEMA, a polymer bearing tertiary amine groups, are interesting and useful materials that show a LCST in water ${ }^{[7]}$. This transition temperature depends on solution conditions such as $\mathrm{pH}^{[8]}$, ionic strength ${ }^{[9]}$ and also on the nature of the anions in solution ${ }^{[6]}$. On the other hand, block copolymers of PDMAEMA and less polar blocks such as poly(methyl methacrylate), PMMA, are materials that form "kinetically frozen" aggregates in aqueous solution that show also LCST, determined by turbidity in a very easy way. Modulation of PMMA- $b$-PDMAEMA LCST is valuable to obtain systems that undergo phase transition at desired temperatures. As mentioned before, the nature of the anions in solution is one of the parameters that affect LCST of such systems.

Ion binding to charged surfaces is an important issue for Chemistry ${ }^{[10-13]}$ and also Life Sciences ${ }^{[14-16]}$. Thus, the study of ion binding on different systems (like polymer aggregates in aqueous solutions) in the presence of urea can shed more light on that phenomenon as well as on the exact mechanism of urea-driven denaturation and other ion binding-related properties of this additive.

Based on previous studies of urea effect on ion binding ${ }^{[5]}$ and as a tool to understand in more depth the mechanism of ion specific influence on the PMMA- $b$ PDMAEMA aggregates, in this work urea effects on the LCST were investigated for this kind of system in presence of several anions.

Corresponding author: Fábio Herbst Florenzano, Departamento de Engenharia de Materiais, Escola de Engenharia de Lorena - EEL, Universidade de São Paulo - USP, Estrada Municipal do Campinho, s/n, CEP 12602-810, Lorena, SP, Brasil, e-mail: fhfloren@gmail.com 


\section{Methods}

Poly(methyl methacrylate)-block-poly[(2dimethylamino)ethyl methacrylate], PMMA- $b$-PDMAEMA (Figure 1), was synthesized via Reversible AdditionFragmentation Chain Transfer (RAFT). Average total molar mass was determined as $66.1 \mathrm{~kg} \cdot \mathrm{mol}^{-1}$, being the PMMA block of $5.4 \mathrm{~kg} \cdot \mathrm{mol}^{-1}$ and the PDMAEMA block of $60.7 \mathrm{~kg} \mathrm{~mol}^{-1}$ (PDMAEMA/PMMA mass ratio $=11.2$ ). Details on the synthesis and characterization can be found elsewhere ${ }^{[17]}$.

PMMA- $b$-PDMAEMA aqueous solutions were prepared by adding proper amounts of concentrated copolymer acetone solution into the aqueous buffered solution (in presence or absence of urea) under magnetic stirring to reach always $0.1 \mathrm{~g} \mathrm{~L}^{-1}$ of the copolymer in the aqueous solution. Acetone final concentration in water was $1 \%(\mathrm{v} / \mathrm{v})$ for all systems studied. LCST measured have not shown significant discrepancy for selected samples having $0.5 \%, 1 \%$ and $2 \%(\mathrm{v} / \mathrm{v})$ of acetone.

For LCST determination, the copolymer solutions were kept in a $3 \mathrm{ml}$ cuvette inside a Biochrom Libra s22 spectrophotometer. The transmittance ( $\mathrm{t}$ ) at $450 \mathrm{~nm}$ was used to determine the LCST, which was considered as being the onset of transmittance drop, defined by the intersection of the linear regions below and above it. The LCST did not vary significantly due to changes on the heating rate. The actual temperature in the cuvette was measured constantly by a Minipa MT-600 thermocouple (type K). The solution $\mathrm{pH}$ was checked at room temperature just before the beginning of each one.

\section{Results and Discussion}

Figure 1 shows PMMA- $b$-PDMAEMA chemical structure. The $\mathrm{pKa}$ of the amine group is around $8^{[18]}$, so that, at neutral and acid $\mathrm{pH}^{\prime} \mathrm{s}$, most of the nitrogen is protonated in aqueous solution. Under such conditions and above the critical micelle concentration $\left(\sim 10^{-3} \mathrm{~g} \mathrm{~L}^{-1}\right)^{[17]}$ the copolymers are aggregated (DLS data not shown) into positive charged micelles ${ }^{[6]}$.

As can be seen in Figure 2, urea has a dramatic impact on how the ionic strength changes the LCST. This effect also depends strongly on the anion nature when in water. Urea nearly equalizes the so-called chaotropic anions such as perchlorate and tiocyanide to other anions, as far as LCST change is concerned. In absence of urea, the chaotropic anions have a strong effect decreasing LCST and are the most affected by the additive. For comparation, in the same concentration and $\mathrm{pH}$, the LCST changes approximately $15^{\circ} \mathrm{C}$ when one goes from no urea to urea $4 \mathrm{~mol} \mathrm{~L}^{-1}$ in $\mathrm{NaClO}_{4}\left(9 \times 10^{-2} \mathrm{~mol} \mathrm{~L}^{-1}\right)$. In the same conditions, in $\mathrm{NaF}$, that difference drops down to less than $4^{\circ} \mathrm{C}$. It is quite remarkable that in high urea concentrations the LCST values for all ions seem to converge to approximately $50^{\circ} \mathrm{C}$. To the best of our knowledge, this is the first demonstration of urea influence on ion binding to this kind of charged polymeric micelles.

In Figure 3 it is demonstrated that urea not only decreases ion specificity but also affects the way the

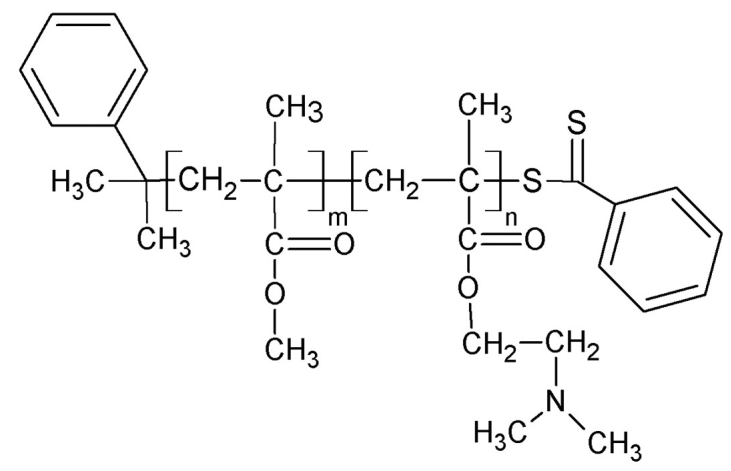

Figure 1. The copolymer PMMA- $b$-PDMAEMA obtained by RAFT used in this work. The indexes " $m$ " and " $n$ " were estimated by GPC as being 53 and 381 in average, respectively ${ }^{[17]}$.

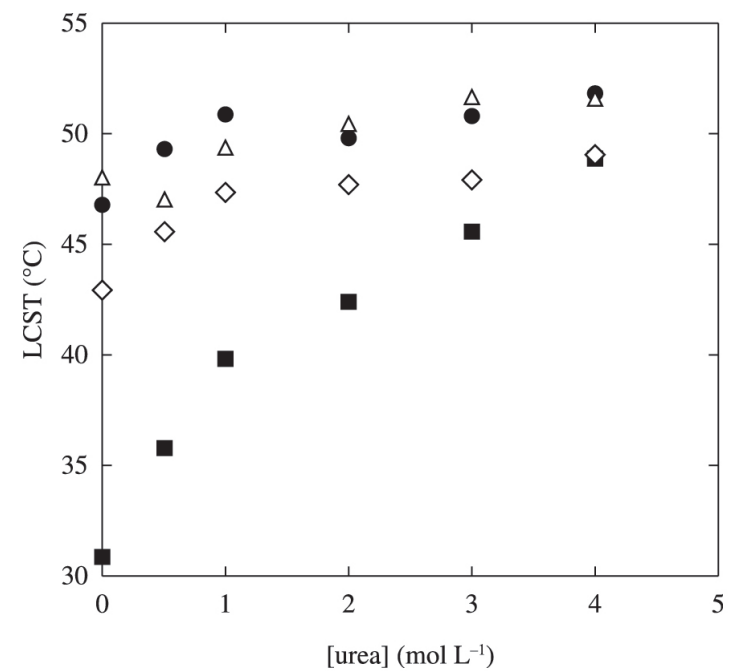

Figure 2. Urea effect on the LCST of PMMA- $b$-PDMAEMA in phosphate buffer $\left(0.025 \mathrm{~mol} \mathrm{~L}^{-1}, \mathrm{pH}=7.9\right)$ and $0.09 \mathrm{~mol} \mathrm{~L}^{-1}$ of different salts. $(\bullet) \mathrm{NaCl} ;(\Delta) \mathrm{NaF} ;(\diamond) \mathrm{NaSCN} ;(\bullet) \mathrm{NaClO}_{4}$.

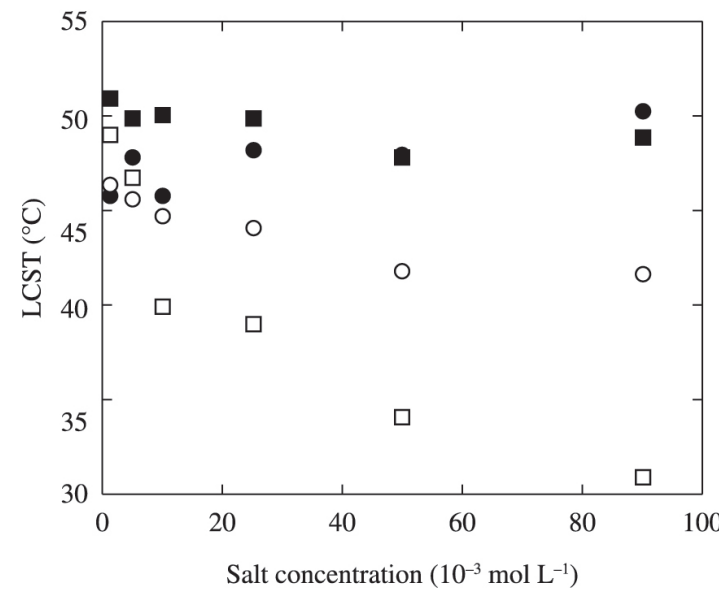

Figure 3. LCST of PMMA- $b$-PDMAEMA at different salt concentrations. $\mathrm{NaCl}$ : (०) no urea; $(\bullet)$ in urea 4 mol.L $\mathrm{L}^{-1}$. $\mathrm{NaClO}_{4}$ : () no urea; (घ) in urea 4 mol. $\mathrm{L}^{-1}$. All experiments in phosphate buffer $\left(0.025 \mathrm{~mol} \mathrm{~L}^{-1}, \mathrm{pH}=7.9\right)$. The LCST with no additional salt, in urea $4 \mathrm{~mol} \mathrm{~L}^{-1}$ and phosphate buffer $0.025 \mathrm{~mol} \mathrm{~L}^{-1}, \mathrm{pH}=7.9$, is $(45.3 \pm 0.9)^{\circ} \mathrm{C}$. 
anion (in that case chloride and perchlorate) concentration changes the LCST values. In absence of urea, perchlorate and chloride concentrations have quite different influence on the LCST. Perchlorate has a stronger effect, decreasing the LCST (hollow squares). In the same figure, it is possible to see that, in urea $4 \mathrm{~mol} \mathrm{~L}^{-1}$, the increasing of perchlorate concentration has only a mild effect, comparable to chloride (solid spheres and squares for urea $4 \mathrm{~mol} \mathrm{~L}^{-1}$ ). This is another evidence of urea acting as an ion binding modulator, reducing the specific differences shown by anion at the same concentration. It is important to note that phosphate buffer $0.025 \mathrm{~mol} . \mathrm{L}^{-1}$ is always present, so it is likely that in Figure 3 one sees, in fact, ion exchange. At low salt concentration, the aggregate positive charged surface is binding mostly monohydrogen phosphate $\left(\mathrm{HPO}_{4}^{2-}\right)$ and, as chloride or perchlorate concentration increases, phosphate is exchanged with that anion.

Although there are many plausible explanations for the effects presented here, taking into account previous studies, it is likely that urea is affecting the way the anions bind (and exchange) to the positively charged interface of the polymer micelles, as it does to other similar systems ${ }^{[2,19]}$. It has been proposed that urea gets into the solvation layers impairing close contacts of the ion with charged surface to make specific interactions. In that fashion, all the ions at high urea concentration behave as solvated species and the interaction with an opposite charged surface is roughly the same for all of them ${ }^{[2,3,5]}$. In opposition to higher concentrations where other effects can be claimed ${ }^{[16]}$, the explanation based on ion binding is preferred because salt concentrations studied here are relatively low (up to $\sim 0.1 \mathrm{~mol} \mathrm{~L}^{-1}$ ) where the electrostatic interactions are dominant.

More studies are necessary to understand the exact mechanism of how urea affects LCST of PMMA- $b$ PDMAEMA systems and similar ones, but it is clear by the results shown here that the magnitude of urea influence on both the thermoresponsiveness and the ion effects on it are very significant for such systems, what makes this additive very promising as a property modulator in this context.

\section{Conclusions}

Urea increases the LCST of PMMA- $b$-PDMAEMA in buffered aqueous solutions in the presence of different salts, but the magnitude of the effect depends strongly on the ion nature, being more significant for the so-called chaotropic ions like perchlorate. Results were understood as due to urea influence on the anion binding to the positive charged surface of PMMA- $b$-PDMAEMA aggregates in aqueous solution. At high urea concentrations $\left(\sim 4 \mathrm{~mol} \mathrm{~L}^{-1}\right)$ all the anions behave quite similarly and LCST is no longer dependent on the ion nature. To the best of our knowledge, this is the first time that loss of specificity of anion binding by urea is reported for positive polymer micelles. This work has enlarged the number of systems on which urea somehow changes processes mediated by ion binding and it is in agreement with what is seen on micelles and vesicles, even though the exact mechanism of urea effect on LCST and ion binding is still an open field.

\section{Acknowledgements}

FAPEMIG, FAPESP and CNPq for the financial support. JCPS acknowledges FAPEMIG and CNPq for his scholarship. The authors thank Dr. J. M. S. da Silva for kindly providing the LCST instrumentation.

\section{References}

1. Florenzano, F. H. \& Politi, M. J. - Braz. J. Med. Biol. Res., 30, p.179 (1997). http://dx.doi.org/10.1590/S0100879X1997000200004. PMid:9239302

2. Dias, L. G.; Florenzano, F. H.; Reed, W. F.; Baptista, M. S.; Souza, S. M. B.; Alvarez, E. B.; Chaimovich, H.; Cuccovia, I. M.; Amaral, C. L. C.; Brasil, C. R.; Romsted, L. S. \& Politi, M. J. - Langmuir., 18, p.319 (2002). http://dx.doi.org/10.1021/ la010176u.

3. England, J. L. \& Haran, G. - Annu. Rev. Phys. Chem., 62, p.257 (2011). http://dx.doi.org/10.1146/annurevphyschem-032210-103531. PMid:21219136

4. Zhang, Y. \& Cremer, P. S. - Annu. Rev. Phys. Chem., 61, p.63 (2010). http://dx.doi.org/10.1146/annurev. physchem.59.032607.093635. PMid:20055667

5. Florenzano, F. H.; dos Santos, L. G. C.; Cuccovia, I. M.; Scarpa, M. V.; Chaimovich, H. \& Politi, M. J. - Langmuir., 12, p.1166 (1996). http://dx.doi.org/10.1021/la9505834.

6. de Souza, J. C. P.; Naves, A. F. \& Florenzano, F. H. - Colloid Polym. Sci., 290, p.1285 (2012). http://dx.doi.org/10.1007/ s00396-012-2651-9.

7. Gao, J.; Zhai, G.; Song, Y. \& Jiang, B. - J. Appl. Polym. Sci., 107, p.3458 (2008). http://dx.doi.org/10.1002/app.26683.

8. Xiong, Z.; Peng, B.; Han, X.; Peng, C.; Liu, H. \& Hu, Y. - J. Colloid Interface Sci., 356, p.557 (2011). http://dx.doi. org/10.1016/j.jcis.2011.01.067. PMid:21316062

9. Wesley, R. D.; Dreiss, C. A.; Cosgrove, T.; Armes, S. P.; Thompson, L.; Baines, F. L. \& Billingham, N. C. - Langmuir., 21, p.4856 (2005). http://dx.doi.org/10.1021/la046830y. PMid: 15896023

10. Romsted, L. S. - Langmuir., 23, p.414 (2007). http://dx.doi org/10.1021/la062411k. PMid:17209589

11. Zhang, Y.; Furyk, S.; Sagle, L. B.; Cho, Y.; Bergbreiter, D. E. \& Cremer, P. S. - J. Phys. Chem. Comm., 111, p.8916 (2007). http://dx.doi.org/10.1021/jp0690603.

12. Tobias, D. J. \& Hemminger, J. C. - Science., 319, p.1197 (2008). http://dx.doi.org/10.1126/science.1152799. PMid:18309069

13. Ninham, B. W. \& Yaminsky, V. - Langmuir., 13, p.2097 (1997). http://dx.doi.org/10.1021/la960974y.

14. Moreira, L.; Bostrom, M.; Ninham, B.; Biscaia, E. \& Tavares, F. - Colloids Surf. A Physicochem. Eng. Asp., 282-283, p.457 (2006). http://dx.doi.org/10.1016/j.colsurfa.2005.11.021.

15. Zhang, Y. \& Cremer, P. S. - Curr. Opin. Chem. Biol., 10, p.658 (2006). http://dx.doi.org/10.1016/j.cbpa.2006.09.020. PMid: 17035073

16. Kunz, W. - Curr. Opin. Colloid Interface Sci., 15, p.34 (2010). http://dx.doi.org/10.1016/j.cocis.2009.11.008.

17. de Souza, V. V.; Noronha, M. L. C.; Almeida, F. L. A.; Prado, C. A. R.; Doriguetto, A. C. \& Florenzano, F. H. - Polym. Bull., 67, p.875 (2011). http://dx.doi.org/10.1007/s00289-011-0508-x.

18. Merle, Y. - J. Phys. Chem., 91, p.3092 (1987). http://dx.doi. org/10.1021/j100295a089.

19. Souza, S. M.; Chaimovich, H. \& Politi, M. J. - Langmuir., 11, p.1715 (1995). http://dx.doi.org/10.1021/la00005a047. 